\title{
Isolated splenic metastasis in a patient with two distinct genitourinary malignancies
}

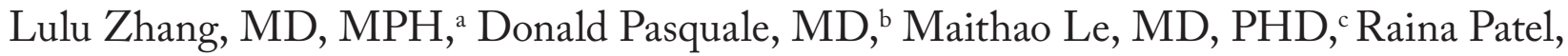
$\mathrm{MD},{ }^{\mathrm{d}}$ and Syed Mehdi, MD

${ }^{a}$ Department of Internal Medicine, Albany Medical Center, Albany, New York; ${ }^{b}$ Division of Hematology-Oncology, Department of Internal Medicine; 'Department of Surgery; and dDepartment of Pathology, Stratton Veterans Affairs Medical Center, Albany, New York

S plenic metastisis is rare, occurring in $2.3 \%$ $7.1 \%$ of cases, of which $95 \%$ are carcinomas. ${ }^{1}$ The lung is the most common primary tumor site ( $21 \%$ of cases), followed by the grastrointestinal system, breast, ovaries, and skin. In a retrospective study evaluating the clinical and pathological impact of splenic metastases during a 25-year period in China, it was found that about $5.3 \%$ of metastases were isolated splenic metastasis. ${ }^{2}$ Isolated splenic metastasis from kidney cancer is very rare and is often an incidental finding. Here we report a case with isolated splenic metastasis in a patient with both primary renal cell carcinoma and prostate cancer, which turned out to be metastatic renal cell carcinoma in the spleen.

\section{Case presentation}

A 67-year-old white man was diagnosed with renal cell carcinoma of the left kidney and underwent a left radical nephrectomy in February 2012. Postoperation staging was stage III (pT3aN0M0), with tumor invasion beyond the capsule but contained within the Gerota's fascia. Pathology showed clear-cell and tubulopapillary features but overall unclassified renal cell carcinoma.

The patient remained in remission for 2 years, until he presented to the hospital with a 2-month history of generalized fatigue, dyspnea on exertion, and a 30-1b weight loss. A laboratory workup revealed that he was anemic with hemoglobin of $10.3 \mathrm{~g} / \mathrm{dL}$ (normal range, male, 13.5-17) and hematocrit of $34.1 \%$ (normal range, male, 38\%-50\%). A computed-tomography scan of the chest, abdomen, and pelvis without contrast revealed an enlarged heterogeneous spleen, with focal nodularity along the superior aspect of the spleen (Figure 1).

A subsequent positron-emission tomograpghyCT scan showed a large, isolated hypermetabolic mass involving most of the spleen, with SUV 16.7 (Figure 2). He had a fine-needle aspiration biopsy of the spleen, and the results confirmed renal cell carcinoma (PAX8 positive, PSA negative) in May 2014.3 A brain magnetic resonance imaging scan and a bone scan did not reveal any other metastasis. He was diagnosed with isolated splenic metastasis that had resulted from renal cell carcinoma. A splenectomy was performed in June 2014. The final pathology also confirmed the diagnosis (Figure 3).

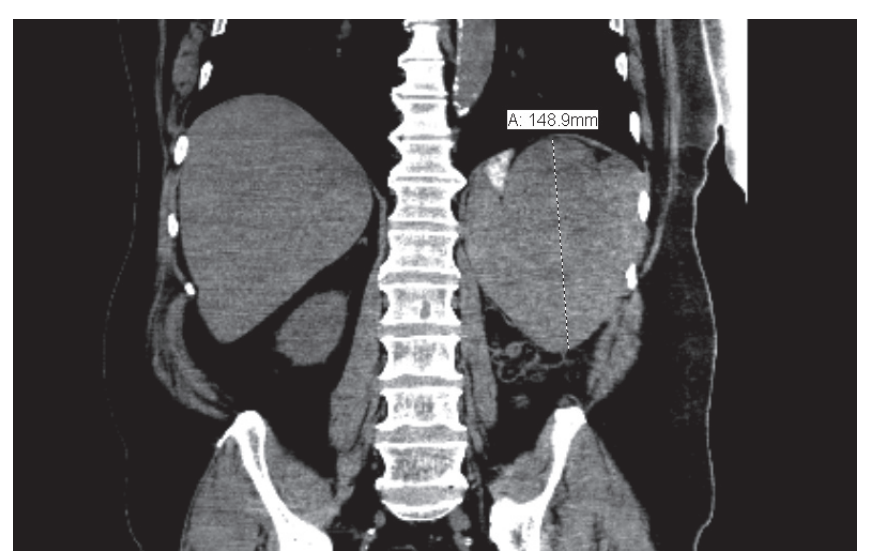

FIGURE 1 A computed-tomography scan of the chest, abdomen, and pelvis without contrast showed an enlarged heterogeneous spleen, measuring $8.8 \times 13.8 \times 14.9 \mathrm{~cm}$, with focal nodularity along the superior aspect of the spleen (May 1, 2014).

Accepted for publication November 20, 2014. Correspondence: Lulu Zahng, Zhangl1@mail.amc.edu. Disclosures: The authors have no disclosures. JCSO 2015;13:229-230. @2015 Frontline Medical Communications. DOI 10.12788/ jcso.0143. 


\section{Case Report}

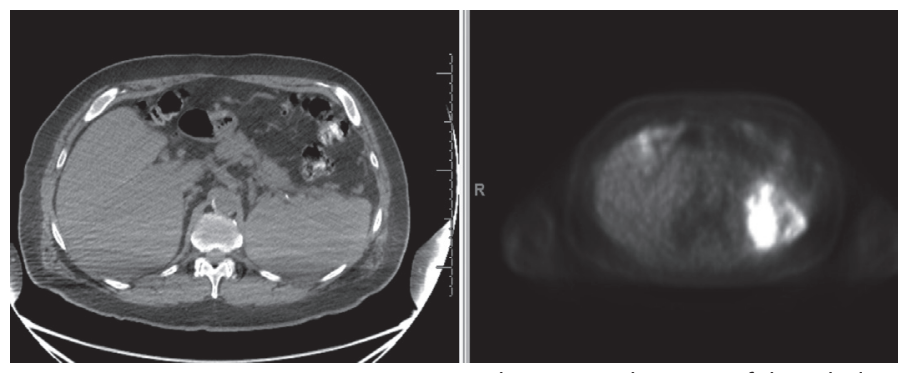

FIGURE 2 A positron-emission-computed tomography scan of the whole body showed an isolated hyper-metabolic mass involving most of spleen, measuring $10.5 \times 7.3 \times 11.4 \mathrm{~cm}$ axially with SUV 16.7 (May 2, 2014).

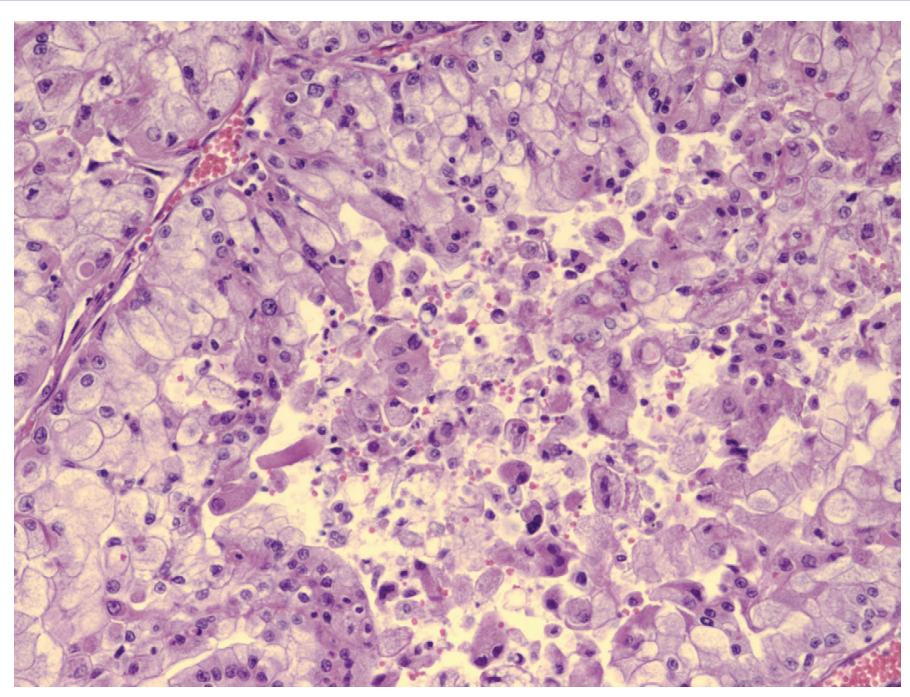

FIGURE 3 Pathology of metastatic renal cell carcinoma in spleen ( $\times 200$, high power)

The patient had a past medical history of prostate adenocarcinoma stage II (pT1cN0M0, Gleason Score 3+4), with a tumor extending to the margins at the apex and bladder neck, status post open radical retropubic prostatectomy in July 2010. He received salvage radiation to the prostate fossa and pelvic lymph nodes for an increasing prostatespecific antigen level in January 2014. At the time of publication, the patient remains in remission.

\section{Discussion}

Surgery is the only curative treatment for kidney malignancies. However, about $20 \%-30 \%$ of patients relapse within 3 years, with the disease metastasizing mainly in the lungs, bones, surgical site, brain, liver, and contralateral kidney.4 A spleen metastasis resulting from renal cell carcinoma is relatively rare. It is usually a part of a multivisceral metastatic disease. In a series of 1,155 renal cell carcinoma patients, 29\% had metastatic disease. However, only 1 patient had splenic metastasis, which was not an isolated spleen involvement. ${ }^{5}$ To our knowledge, only about 9 cases of isolated splenic metastasis in renal cell carcinoma have been reported as of the printing of this article. ${ }^{6,7}$

The possible reasons that splenic metastases in nonlymphoid tumors are rare include: the sharp angle at the origin of the splenic artery, the rhythmic contraction of the splenic sinusoids, the scarcity of lymphatic vessels extending into the parenchyma, the protective role of the splenic capsule and the microenvironment that inhibits the growth of cancer cells. ${ }^{8}$ The best treatment for isolated spleen metastasis in any type of cancer is still debatable, given the small number of patients available for study. A splenectomy seems to increase the length of survival; but did not show any statistical significance in one study. ${ }^{5}$ The role of tyrosine-kinase inhibitors in the management of resected isolated metastasis from renal cell carcinomas is still unknown.

\section{References}

1. Compérat E, Bardier-Dupas A, Camparo P, Captron F, Charlotte F. Splenic metastases: clinicopathologic presentation, differential diagnosis, and pathogenesis. Arch Pathol Lab Med. 2007;131:965-969.

2. Lam K, Tang V. Metastatic tumors to the spleen: a 25-year clinicopathologic study. Arch Pathol Lab Med. 2000;124:526-530.

3. Singh AK, Shankar S, Gervais DA, Hahn PF, Mueller PR. Image-guided percutaneous splenic interventions. Radiographics. 2012;32:523-534.

4. Chae EJ, Kim JK, Kim SH, Bae SJ, Cho KS. Renal cell carcinoma: analysis of postoperative recurrence patterns. Radiology. 2005;234:189-196.

5. Sauer J, Sobolewski K, Dommisch K. Splenic metastases-not a frequent problem, but an underestimate location of metastases: epidemiology and course. J Cancer Res Clin Oncol. 2009;135:667-671.

6. Moir JA, Sen G, Saif, Haugk B, French JJ. Isolated splenic metastasis from renal cell carcinoma: case report and review. Case Rep Gastroenterol. 2011;5:166-171.

7. Nunes TF, Szejnfeld D, Miiji LN, Goldman SM. Isolated metachronous splenic metastasis from renal cell carcinoma after 5 years. BMJ Case Rep. 2012; doi: 10.1136/bcr-2012-006992.

8. Saad G, Hussein M, El-Saghir NS, Termos S, Sharara AI, Shamseddine A. Isolated splenic metastasis from colorectal cancer. Int J Clin Oncol. 2011;16:306-313. 